\title{
Teacher educators' perceptions of their profession in relation to the digitalization of society
}

\author{
Anna Roumbanis Viberg, Karin Forslund Frykedal, and Sylvana Sofkova \\ Hashemi $^{1}$
}

\begin{abstract}
This study takes an exploratory approach to investigating Swedish teacher educators' perceptions regarding their profession in relation to the digitalization of society and education, including higher education. Eighteen semi-structured interviews were analyzed using thematic analysis. Findings show that the teacher educators perceive digitalization on a scale that ranges from simply using tools to being part of a technology-initiated revolution of educational institutions and society. From this range of digital developments emanate individual, group, and organizational requirements/demands, needs, and consequences for being, that is, personal experiences of how digitalization affects the work, and acting, that is, doing something in response to the demands of using and teaching with digital technology. The teacher educator is situated primarily in being with the requirements for working professionally and acting as a teacher, which creates tensions and challenges for the individual and the professional self. Teacher educators require support to strengthen their professional identity, to facilitate activities for professional development, and to stimulate reflective practice. A further difficulty is the lack of relevant policies and strategies. This study highlights the complex challenge of teaching and learning simultaneously in a profession that implicates autonomy and responsibility of its practitioners. This creates limitations for the teacher educators to move from being to acting.
\end{abstract}

Received 31 August 2019; revised version received 8 October 2019; accepted 28 October 2019. Corresponding author: Anna Roumbanis Viberg, University West, Sweden (anna.roumbanis-viberg@hv.se).

\footnotetext{
${ }^{1}$ This study was supported by the research environment LINA (Learning in and for the new working life) at University West, Sweden. The authors declare no potential conflict of interest with respect to the research, authorship, and/or publication of this article. The authors thank the participating teacher educators for their interest, and for bringing valuable insight into the researched matter.
} 


\section{Introduction and aim}

The purpose of education is to help students, who are citizens, or citizens of the future, to develop an understanding of our world. The rapid expansion of digital technology is changing the ways we communicate, make meaning, and learn, which in turn affects education. Thus, education is in a process of change that requires a relevant development reflecting contemporary society. In the case of school education, such a change takes time and requires equipping future school teachers with the skills that meet the demands of a digitalized society. Consequently, changes also need to be made to higher education and its contexts and programs, teacher education being one of these programs. This, in turn, entails changes in teacher educators' professional identity and work (Jonker et al., 2018; Selwyn, 2017). There are differences between teacher education programs around the world; they have varying goals, structure, and organization since their purpose is to educate those who will teach a particular nation's citizens. This study is in a Swedish context, where the national Teacher Education Program is offered within higher education.

In Sweden, a national strategy for the digitalization of education was launched in 2017 with an overall aim to give students the opportunity to develop the ability to use and create with digital technology and understand how digitalization affects the individual and society (Swedish Ministry of Education, 2017). The digitalization of schools in Sweden has been an ongoing process since the late 1970s, mainly supported by state funding for shifting reasons and during specific periods of time. Nowadays Swedish schools report the highest figures in Europe for computer density (OECD, 2017). Similar initiatives have not been implemented to the same extent in relation to teacher education in Sweden, which, like many other pre-service teacher programs around the world, faces challenges preparing future teachers for digitalized education in schools (Gudmundsdottir \& Hatlevik, 2017; Istenic Starčič et al., 2016; Mouza et al., 2014). The aim of this study is to explore teacher educators' (TEs') perceptions of their profession in relation to the digitalization of society and skills needed in the future. The goal is to provide an in-depth understanding of how changes in schools and higher education that coincide with digitalization affect the TE's profession and the conditions for developing the pre-service teachers' readiness to teach and work in a digitalized school.

\section{Digitalization in the educational sector and higher education}

Digitalization is described by Brennen and Kreiss (2016) as 'the way many domains of social life are restructured around digital communication and media infrastructures' (p. 1) and by Fors (2010) as embedded in 'most aspects of our 
lives, the world increasingly becomes impregnated by, with and through the digital' (p. 29). Thus, technology-related changes affect the entire society and its inhabitants. The pace of change in the implementation of digital technology has differed between the public context and the educational sector (from pre-school education to higher education). Selwyn (2017) suggests that the digitalization of the educational sector can perhaps best be understood as 'further development of non-digital processes and practices /.../ creat[ing] new opportunities while bringing new limitations and unwanted consequences' (p. 15); for example, consequences such as the uncritical adoption of digital tools and unhelpful reproduction of existing practices. Furthermore, Selwyn (2017) discusses the normative and positively-loaded rhetoric behind digitalization in terms of three different levels of impact: as technology that improves teaching, as something which transforms processes and practices, or something that leads to an educational revolution. Selwyn (2017) implies that these conceptions concern the whole educational system and extensively influence teacher education, and thus teacher educators.

Castañeda and Selwyn (2018) put forward a need for critical reflection and discussion on the complexity of digitalization as a response to a rhetoric of a hyped nature, and raise some overarching issues concerning digitalization of higher education. First, there is the need to talk about learning and pedagogy, to dig deeper into understanding what technology-based learning actually is, and how the use of technology shapes, conditions, and modifies instruction and pedagogy (see also Bartolomé et al., 2018; Decuypere \& Simons, 2016). Second, we need to acknowledge that digital technology in higher education 'profoundly shapes the emotions, moods and feelings of students and staff' (Castañeda \& Selwyn, 2018, p. 4) and examine how this affects higher education and the individuals involved in it. And third, we need to understand how digital technology has created individualized educational paths, an increased responsibility placed on the individual to learn and be self-motivated, and with that a decreased possibility of socialization and education becoming democratic and inclusive (Castañeda \& Selwyn, 2018). In this paper the concept of digitalization is viewed as a process of change, including the three levels of impact described above by Selwyn (2017).

\section{TE in a digital era}

The TE differs from other university lecturers with the assignment of teaching to teach, that is, second-order teaching, representing what will be the students' future profession (Berry, 2009; Korthagen et al., 2005; McGee \& Lawrence, 2009). TEs are a heterogeneous group with different backgrounds, working in diverse settings, with a variety of tasks that relate to several different roles or functions 
(Koster et al., 2008; Lunenberg, 2010). Lunenberg et al. (2014) found six professional roles that TEs have to play: teacher of teachers, researcher, coach, curriculum developer, gatekeeper (for the students), and broker (to stimulate the cooperation between schools and institutions). Digitalization has an influence in various ways on all these professional roles. The TE is thus, on a daily basis, faced with a challenge to balance these roles, which can complicate decisions about where to invest energy and what to emphasize.

The TE's identity construction is described as ongoing and fluid, involving negotiation between past experiences, new ideals, necessary skills, agency, and constraints (Trent, 2013). For example, TEs' past experiences can collide with new challenges in terms of, for example, their acquired knowledge and acting in new learning environments. The ongoing changes in society, schools, and higher education with regard to digitalization require the TE to be innovative and willing to change. Drent and Meelissen (2008) argue that TEs who use digital technology innovatively have a certain type of identity, with a particular combination of knowledge, skills, and attitudes. The authors call them 'personal entrepreneurs'. They have the following characteristics: a positive attitude towards digitalization of education and society; regard for digital competence as part of a student-active pedagogical approach; willingness to take responsibility for their own information and communications technology (ICT) professional development. Avidov-Ungar and Forkosh-Baruch (2018) have recently examined TEs' perceptions regarding their pedagogical innovation in the digital era, using three modes of existence as a theoretical framework. There is the being-mode, the conceptual aspect of their identity; the doing-mode, the practical aspect; and finally, the having-mode, which is the environmental support aspect, that is, what the TE needs from, for example, colleagues. The authors found that educational practice in the digital era makes TEs re-examine their professional identity, that is, the being-mode, to a greater extent than the other two.

Knight et al. (2014) identify a general research gap, namely that the TE as an important field to understand second-order teaching has been an area of lesser interest. When it comes to research on digitalization within teacher education, focus has been primarily on studies about teaching with technology and the development of students' digital competence (Farjon et al., 2019; Harvey \& Caro, 2017; Instefjord \& Munthe, 2016). Studies on TEs' work and what role digital technology plays in being a lecturer working in higher education are few (e.g., Gerbic, 2011; Kim et al., 2013; Uerz et al., 2018). Digital technology creates new prerequisites for the teaching profession and the practice that the individual lecturer has to relate to and cope with. The TEs' construction of who they are as educators in relation to digitalization in turn affects the pre-service teachers' 
ability to develop a professional identity. Therefore, research on this topic is needed.

\section{Theoretical lens - the TE's professional development}

The TE's professional identity as an educator can be seen as a response to participation in a practice and to their experience, learning, and knowledge of the profession (Kolb, 2014; Wenger \& Wenger Trayner, 2015). According to Reich and Hager (2014), practice in a professional context can be explained as 'a collective and situated process linking knowing, working, organizing, learning and innovating' (p. 421). To create collective learning and a practice with a sense of belonging to a professional community, Wenger and Wenger Trayner (2015) argue for creating a community of practice where domain, community, and practice are in play and in transition. 'Domain' represents here the group's identity, 'community' is the engagement between community members in purposeful activities and interprofessional learning, and 'practice' is the shared repertoire of resources. Patton and Parker (2017) conclude that when TEs are part of a community of practice, the collegial collaboration and the development of teaching and research abilities are increased. Based on the Wenger and Wenger Trayner's (2015) conception of a community of practice, Hadar and Brody (2010) propose a three-layered model for building a professional development community (PDC) among TEs, where the layers build upon one another (see Fig.1).

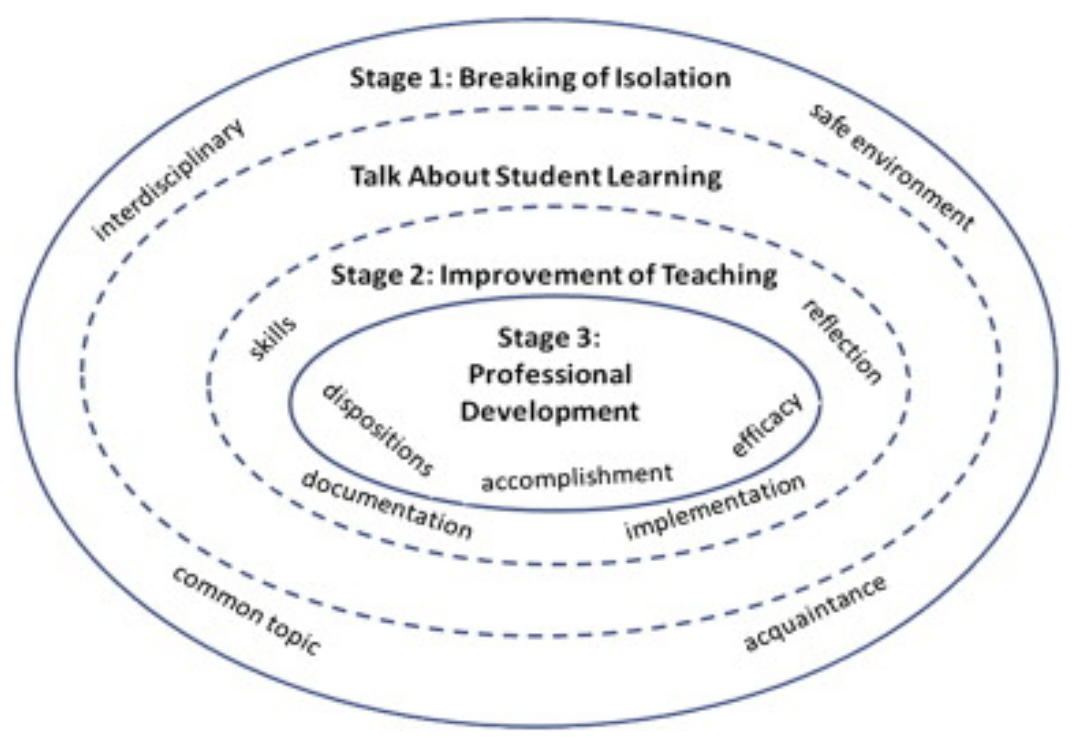

Figure 1. Layered model of professional development based on the PDC paradigm (Hadar \& Brody, 2010). 
The first layer, called 'breaking the isolation', relates to the solitary nature of the work TEs do, with its limited opportunities for collegial interchange, including factors such as a safe environment, having a common topic, interdisciplinarity, and acquaintance. The isolation can be used by the TE to restrict and protect the professional practice, which could be a factor that delays the professional development process (Snow-Gerono, 2005). In the second layer, 'improvement of teaching', the TE is gaining new knowledge and skills and reflects collegially. Skills, reflection, implementation, and documentation are important factors. Finally, in the third layer, 'professional development', factors such as efficacy and disposition are stressed. The TE has a feeling of efficacy and a sense of accomplishment. In the present study, Hadar and Brody's (2010) model will be used as a theoretical lens.

\section{Method}

The study was designed in accordance with a qualitative research approach and inductive analysis. In order to explore the TEs' perceptions, semi-structured interviews were carried out. This section describes the context and participants in the study, data collection, and analytical instruments.

\section{The context and participants}

Twenty-seven Swedish universities offer a four-year teacher education program in primary school education. The Primary School Teacher Education Program is divided into three different majors: (a) after-school center education; (b) preschool class education and primary school education, grades $1-3(\mathrm{~K}-3)$; and (c) primary school education, grades $4-6$. In order to receive a teaching degree for grades 4-6, one must fulfil twenty-six intended learning outcomes according to the Swedish Higher Education Ordinance, one of which is related to digitalization: 'Demonstrate the ability to safely and critically use digital tools in educational activities and take into account the importance of different media and the digital environment's role in this' (SFS, 1993:100).

The participants were 18 TEs working on a campus with teacher education programs for primary school education, grades 4-6. Twelve of them were female and six were male, in the age group 30-60 years. In the Swedish Higher Education Ordinance (SFS, 1993:100) there are only regulations for teaching in an institution of higher education, none specifically for teacher education. The statute defines a lecturer as 'a person who has demonstrated teaching expertise and been awarded a $\mathrm{PhD}$ or has the corresponding research competence or some 
other professional expertise that is of value in view of the subject matter to be taught and the duties that it will involve' (SFS, 1993:100). All these different levels of professional background are represented among the participants. The participating TEs had on average 10.6 years of teaching experience as a TE. Fifteen of the 18 TEs had a degree in education and an average of 19.4 years of teaching experience at the elementary or high school level. Ten had PhD degrees, while eight had both a degree in education and a $\mathrm{PhD}$. One participant had neither a degree in education nor a $\mathrm{PhD}$. The participants represent different disciplines and departments.

\section{Data collection and analysis}

Data were collected from four universities in Sweden in June 2017. The four ethical principles based on (a) respect, (b) competence, (c) responsibility, and (d) integrity have been practiced throughout the study (Swedish Research Council, 2019). The four universities differ in several aspects: geographical location, the number of students attending the teacher education program, the plan and structure of the program, and the profile of the university. Details about the universities have been left out since they could otherwise be easily identified. Criterion sampling was applied for gaining information-rich cases and maximum variation (Quinn-Patton, 2002). The criteria for participation was being a TE working with pre-service teachers on a teacher education program for grades 4-6. Four position holders at different universities were contacted and asked to provide names and contact information for all their TEs working on teacher education programs for grades 4-6. The four position holders had leading positions, which may have affected the selection process. The participants may have felt obliged to accept being interviewed, but they were informed that they could terminate their participation at any time without anyone knowing. The TEs were approached and invited via e-mail to participate in the study. Altogether there were 49 TEs contacted, and 24 of them were willing to participate in the study. Eighteen of them were interviewed. The drop in number was due to reasons such as illness and time constraints. The interviews took place at the participants' universities except for two: one was conducted over the phone and one was conducted at another university. All interviews were carried out behind closed doors in offices or the equivalent to ensure a safe environment for the participant and to avoid disturbances. Before the interview, the participants signed a written informed consent.

The structure of the interviews was designed to investigate the following topics: the assignment and everyday work as a TE, contact with the students, and teacher education as part of society. The interviews ended with an invitation to freely reflect upon four vignettes (four quotes) representing statements related in 
one way or another to the digitalization of society, higher education, and teacher education. Vignettes can be a way of exploring the interpretative practices of participants (Jenkins et al., 2010), which was important for this study. Three of the vignettes were identical for all participants: one was from the Swedish Higher Education Ordinance (SFS 1993:100), concerning IT being an essential part of teacher education in phase with the digital developments in society and in the school system; one was from a research article concerning the lack of digital competence in teacher education; and one was from a survey-report investigating how pre-service teachers perceive their education from the perspective of digitalization, conducted by a market research company. The fourth vignette represented a quote from the participants' universities' goals and vision for the future, a future of globalization, new learning environments, and rethinking of education. During the last part of the interview, the participants were given the possibility to add to or comment on the topics discussed. The duration of the interviews was between 50 and 75 minutes (in total 18 h, $20 \mathrm{~min}$ ) and they were recorded with a Dictaphone and transcribed verbatim, comprising 281 pages of transcription.

The transcriptions were coded using the qualitative data analysis software NVivo. A thematic inductive analysis was used, which, according to Braun and Clarke (2006), is a stepwise analysis process in six phases, each with clear guidelines aimed at creating themes. To begin with, each transcript was read repeatedly; this was done to become familiar with the data and to begin searching for patterns and themes relating to the aim of the study (first phase). A sample of three interviews was randomly selected and initially coded to explore the terrain and find a focus for the research. The initial coding resulted in clusters of codes labelled 'possibilities', 'fears', 'challenges', 'needs', 'requirements', and 'expectations'. These code-clusters were used as a starting point for the open coding of the entire empirical material (second phase). The analysis continued with searching for potential themes by comparing and collating codes, clusters of codes and reviewing themes (third phase).

In the comparative analyses, some of the clusters of codes became subthemes and new themes were constructed depending on whether the participants talked about a professional self or the professional practice (fourth phase). In the continuing comparative analyses the themes were related to each other, exploring similarities, differences, and contrasts, and the final themes and subthemes were constructed, defined, and labelled (fifth phase). In the sixth and last phase the manuscript was completed, and the final themes and subthemes have been used to describe the findings. Table 1 shows the number of references (codes) included in each theme and subtheme, demonstrating that the theme being in practice is highly emphasized in the utterances by the participants compared to 
the theme acting in practice. Excerpts are used to illustrate the content and meaning of each theme and subtheme. It should be noted that the analysis covers the variety of perceptions across the group of participants based on representative quotes.

\begin{tabular}{lcc}
\hline Theme - subtheme & No. of interviews & No. of codes \\
& & $\mathbf{1 8 0}$ \\
Being in practice & $\mathbf{1 8}$ & 51 \\
External requirements and inner demands & 15 & 103 \\
Needs in relation to the requirements and demands & 16 & 26 \\
Consequences in being & 11 & $\mathbf{7 9}$ \\
Acting in practice & $\mathbf{1 8}$ & 40 \\
Teaching with digital technology & 15 & 16 \\
Handling technology & 8 & 23 \\
Consequences of acting as an educator & 11 & \\
\end{tabular}

Table 1. The final themes and subthemes - number of interviews and number of codes included in the themes.

\section{Results}

Based on the aim of this study to explore the TE's perceptions regarding their profession in relation to the digitalization of society and the conditions of higher education to develop pre-service teachers' readiness to teach and work in a digitalized school, two themes (a) being in practice and (b) acting in practice were identified in the interview data, described further below.

\section{Being in practice}

The identified theme being in practice concerns the TE's conceptual understanding of being a TE in a digitalized society and teaching pre-service teachers to become professional practitioners in schools in the future, the professional self. Thus, 'being' refers to the personal experiences of how digitalization of society affects the work as a TE, the individual's inclination to grow, learn, and cope. This theme was represented in the data by the following three subthemes: (a) external requirements and inner demands, (b) needs in relation to the requirements and demands, and (c) consequences in being.

\section{(a) External requirements and inner demands}

A large group of the TEs talk about the external requirements and the inner demands they perceive exist when it comes to living in a digital society and using digital technology as a teacher. There are external requirements placed upon the 
TE by society, university administration, and students that demand one has the skills needed to use the digital technology. They say that places demand on the teacher education program and the TEs to adapt to the trends that permeate society. These trends are both made apparent and are regulated by policy. When university administrations implement, for example, digital systems, it is mainly up to the individual TE to learn to handle the digital technology in the workplace: 'one is just thrown into a learning platform and expected to have the knowledge' $(1)^{2}$. Technology must be mastered to be able to do one's job and it is repeatedly being updated and changed. There is a perceived demand for a personal commitment to drive a process of change and at the same time be part of the students' learning process. A TE expresses that in the following way: 'a strong incentive is required for wanting to change the way one works' (11). This is perceived as time-consuming, difficult, and tiring, and, as one TE puts it: 'I'm not prepared to put so much of my energy into it to become excellent' (18). There is a perceived demand from the students to be part of a digitalized program, but also to learn to conduct digitalized teaching. Some of the TEs also experience an expectation from the students that the teacher education program they are attending is up to date: 'I think there is an expectation in some way, that teacher education should be a modern education that keeps up with the times' (11). The TEs have the feeling they cannot achieve this and they say that it is always going to be a problem due to a lack of time and competence. The TEs say they need time to explore and learn how to use the digital tools.

The TEs also talk about the inner demands digitalization has placed upon them to be able to relate to the present. Digitalization is described as 'the reality we live in now' (3). It is not something that has happened or will happen; instead, we are in the midst of it. Some TEs describe digitalization as profound, something that has created a change in the individual's identity, relationships, and ways of thinking. There is an uncertainty about how this affects oneself and others. It is perceived as an inner demand, a must, to be able to relate to contemporary society and that teacher education 'must become a more natural part of how we relate to our times' (3).

\section{(b) Needs in relation to the requirements and demands}

The TEs talk about their needs in relation to the requirements and demands they perceive exist. There is a consistency between the requirements/demands and their needs in terms of knowledge development, but the TEs stress the need to critically reflect upon the use of digital technology and to understand the group they are part of. When society changes, it creates a need to be prepared and a need for more knowledge and competence to 'be updated factually, didactically, and

\footnotetext{
${ }^{2}$ The excerpts are labeled with the number of the interview corresponding to the interviewed participant.
} 
technically' (12). To have knowledge of digital technology is considered by the TEs to be a significant development area. They note the importance of being able to handle 'a new game plan with a new set of rules' (16) and to be able to 'formulate goals that feel relevant when it may be something we have not tried ourselves' (12). It is also stressed that '[i]t has a tendency to become too much that we adapt to trends that are not always so well-founded, there is somebody else who has an interest there' (18). The perceived consequences are that the TEs are not taking the time to reflect upon why digital technology ought to be used. There is a belief that digital technology is being put on a 'pedestal' (5) and to be the 'solution to all problems' (5), which could be a sign of a technical optimism. One TE goes even further and raises a question about the uniqueness of teacher education: ' /.../ we can instead think about what is unique that we can come up with as a complement to people's lifelong learning' (7), and whether digital technology has a role to play in this. A reflection on what purposes there are for the use of digital tools is sought after and not only to 'reproduce what always has been done' (3).

It is also highlighted by some TEs that there is a need to understand the culture of the group of TEs, who are heterogeneous in terms of interest and digital knowledge. There are the enthusiasts 'who are very good at this and then I think for example then the students get it at least from them, which is a really bad excuse for not doing this yourself' (8). Often, these enthusiasts become responsible for the use of digital tools in more courses than their own. Then there are educators who do not have an interest in learning anything new; it is speculated that this is due to the fact that digitalization is seen as 'nothing new under the sun' (6). There is also 'a resistance to change, it takes so much time and effort, so you do not want to do it, one protests wildly' (7). This results in time and effort needed for learning not being prioritized.

However, several of the TEs express the desire for an increased shared responsibility and commitment to digitalization and 'less sharp dividing lines between the various institutions at the university' (11). The fact that the culture of the university 'is an individualistic culture where no one should tell me how to handle my job' (1) is mentioned by one of the TEs as an explanation for why it is difficult to get the group united. Some TEs point out the importance of the collective having digital strategies for the entire teacher education program. They say 'if there is to be a radical change, then it does not just have to land in the lap of the individual teacher, then the teacher education curriculum in general has to state that this is what we should do' (11).

(c) Consequences in being 
The requirement of using digital technology for both professional and student needs can contribute to the TE's feelings of inadequacy, both at work and as a private person. This is an inadequacy which includes both a lack of knowledge and skills. There is an endless development of new technology and new systems to handle, which becomes a necessity to manage in university teaching situations and not all TEs feel that they can manage that: ' $/ . . /$ I do not think that everyone is able to adapt their teaching so that it becomes good, I have a hard time and that is because there is technology that I have not mastered' (18). It becomes a challenge to adapt the teaching to the new circumstances. TEs describe this as a feeling of insecurity, a fear of making mistakes and in the long run not being able to handle the task as an educator. This can lead to stress and contribute to an ever-present bad conscience in their relations with students: 'I should be better, but I do not really know how yet, I have a bad conscience, I have a really bad conscience' (8).

Some of the TEs speak about the fact that there are possibilities for using digital technology since they are given the opportunity to work with other resources and that teaching can be done in other forums. Working on the learning platform has changed the TE's own learning; they learn from students and through social media. Only one participant points out that the technology can mean the possibility for the individual to have a more flexible work situation, a chance to live his/her life in a different way.

\section{Acting in practice}

'Acting in practice' is what the TEs as individuals say they do in their everyday work in a response to the demands within higher education with respect to using and teaching with digital technology. The TEs act; they take a stand to do or not do. In the utterances, there is an awareness that digital technology is part of the contemporary society and higher education teaching, and the individual makes choices related to this. This theme is comprised of three subthemes: (a) teaching with technology, (b) handling the technology, and (c) the consequences of acting as an educator.

\section{(a) Teaching with digital technology}

The TEs encounter the students in various roles and situations but the primary task is to educate. TEs as a group see digital technology primarily as an asset in teaching when there is an added value in using it and when the educator has learned to use the technology. The TEs primarily emphasize that technology has enabled communication and collaborative work: 'I find it much easier to keep in touch with people /.../ creating groups' (1). Several TEs express the feeling that digital technology creates ways to interact with the students; for example, the technology makes it possible for the TE and the student to alternate ways of 
meeting and working, such as via Skype. The technology increases student participation and facilitates collaboration and communication between the TE and the student as well as between the students. Digital technology also provides possibilities for variation in the teaching and thereby enables different ways of motivating students and gaining their enthusiasm. This is described by some TEs as utilizing the technology to its advantage. One TE also describes the use of digital technology as 'another form of representation' (3) that can improve learning and the abilities the student is supposed to develop; it becomes an asset. Thus, the use of digital technology provides possibilities for finding ways for the student to learn; for example, more opportunities are provided for visualizing abstract thoughts in new forms of representation.

\section{(b) Handling the technology}

Unlike the previous subtheme, this theme is primarily about managing and understanding how to use technology, rather than teaching with the technology. Digital technology plays an important role in the work of educators, since they must be able to handle the technology, use the equipment properly, and manage the consequences of using it. Some TEs say that they use the students as a resource in teaching situations, like starting up the technical equipment in the lecture hall. It is not just about believing the student to be more skilled; it is also, as one participant says, 'a way of not taking the time to learn the digital technology' (8). The use of technology allows the students to be both the helper and the technician: 'Very often when I am going to use a digital device in a lecture hall, I ask a student to come and help me and then they get it started' (18).

One TE stresses that with the use of, for example, learning platforms and open forums for comments, the TEs are faced with ethical dilemmas to solve. These ethical questions may concern violations of various kinds, such as spreading rumors, affecting both students and TEs. The digital medium's availability in time and space makes it difficult for TEs to be prepared for this type of event.

Teachers from primary and secondary schools, who are beginning to teach in higher education, are affected by the difference in the use of technology. There are differences in the type of hardware and software available in the teacher education program compared to the schools. As a result, these newly appointed TEs with previous experience of working as school teachers, perceive they must change the way they teach with digital technology, described as going backwards in usage: 'I went backwards nine years when I came here because the students, not all the students have a computer with them' (12).

\section{(c) Consequences of acting as an educator}


When it comes to preparing the pre-service teachers to pursue a teaching profession that will require the use of digital technology, some TEs feel that they do not enable this because they do not have the knowledge and skills. The TEs perceive that in some cases, students learn the technology on the teacher education program by creating, for example, films and searching for literature, but there is little reflection upon the pedagogical use and how digital technology should be used in teaching. The TEs reflect that they should help students make the transition from student to professional user (as a teacher). A participant describes it this way: 'I do not put too much effort into teaching them, and not so much perhaps into reflecting, if they are to reflect on how they can use it themselves in their teaching, perhaps they need to do that more, we help them see such a thing, make the connection, and also see what can work and what does not work' (9). There is an awareness among the TEs that students need time for reflection on what role digital technology should play in education, perceiving their role as TEs to guide the students in these reflections. However, there are also TEs expressing that the students learn the necessary digital skills themselves, often in their practicum (internship).

Being a teacher in general means, among other things, being able to manage a classroom, being able to see what is happening in the classroom and communicating with the students (through eye contact, body language). These are skills that one learns in a professional setting and through experience. The TEs stress the fact that this may be lost if too much is done, for example, via a computer, since the ability to teach the student about the profession is then reduced. For example, the TEs express that direct proximity is difficult to transfer and the subtler signals in a classroom can be difficult to see and teach on a screen. Concerns are also raised that subjects such as arts and crafts will disappear in a more technology-based education. The TEs refer to the way they teach as 'the intelligence of the hand /.../ which is reduced in our adaptation to virtual learning' (18), because of the difficulty in physically showing and using the material.

An additional aspect referred to concerns the opportunities and obstacles of using digital technology in an individualized learning situation. The TEs express that the technology makes it possible for students to access information whenever and wherever they want, which they perceive contributes to a loss of the socialization process that is present in a classroom and in learning situations with fellow students. One TE sums it up this way: 'it is difficult to be a teacher, a good teacher, with these new media. If it was only about transferring information, then it is working but it is not that simple being a teacher' (18).

\section{Discussion}


The analysis of the empirical material demonstrates that the TEs being and acting in practice are affected by digitalization on an individual, group, and organizational level (see Fig. 2). The TEs perceive that there are requirements, explicit and implicit, and needs that permeate these three levels. The explicit requirements of the TE, as an individual, concern, in particular, being the carrier of the knowledge base and also inner demands regarding being digitally competent and in constant learning mode. In fulfilling these requirements and demands, the TE feels alone and inadequate, expressing a need for knowledge acquisition and professional development. In turn, the TE perceives an obligation to master technology in everyday life and in preparing the student for the profession as it is now practiced in a digital society. On the group level, the TE is part of a 'semi-digital' culture - a culture of participants who differ in knowledge and motivation to learn about and ponder digital technology and use their professional autonomy in various ways. In this respect, the TEs express a desire to become members of a community that facilitates opportunities to learn, explore, and critically reflect upon digital technology in the teaching profession. On the organizational level, the TEs find teacher education trend-sensitive. They perceive that existing guidelines, strategies, and the administration of a teacher education program in the digital age, are vague and few.

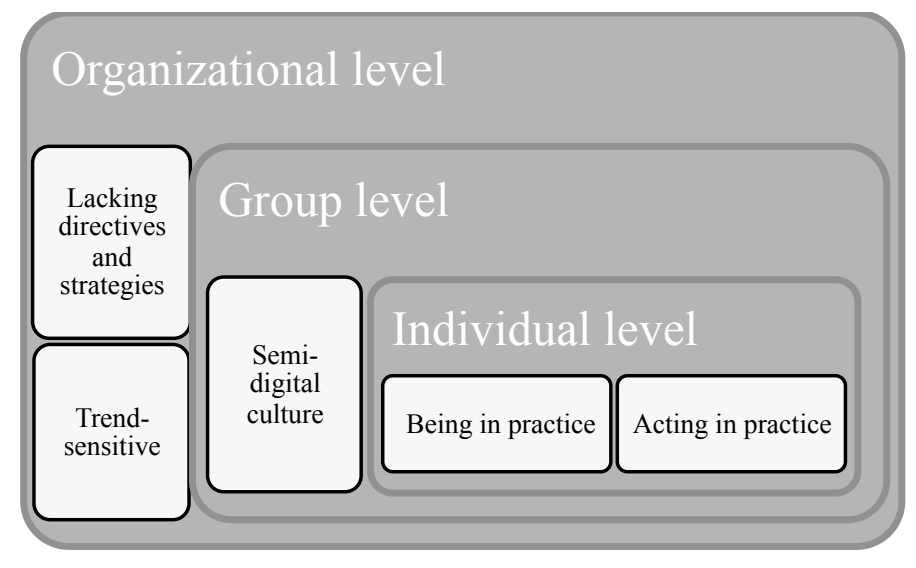

Figure 2. Digitalization in relation to TE.

Furthermore, the identified theme being in practice is more strongly emphasized in the empirical material in comparison to the theme acting in practice. That is, similar to the Avidov-Ungar and Forkosh-Baruch (2018) study, the TEs emphasize and talk more about being a professional practitioner and how digitalization affects the professional self (knowledge, skills, and sense of self) than the professional practice, acting as a TE. In accordance with these findings, 
the TE is thus located primarily in being in practice with the requirements for working professionally, which creates tensions and challenges for the individual and the professional self on several levels. The empirical material identifies three such tensions.

The first tension concerns requirements affecting the professional self with the consequences of learning with a responsibility to teach and a feeling of loneliness. Being a professional in constant learning mode is nothing new; however, as a TE, who has teaching as his/her teaching subject, not having the required knowledge in relation to digitalization in education creates an inner demand and a complex situation.

The complexity derives from the need to be teaching and learning simultaneously when being responsible for second-order teaching. This is a state of affairs that requires reflection on the teaching content and its impact on the preservice teacher's future career, a reflection emphasized by Castañeda and Selwyn (2018). Thus, the requirements and demands of having knowledge and skills affect both the TE's personal and professional self. The study's findings show that the TEs perceive themselves in general as not being capable and competent, where their perceived lack of digital competence creates an inner demand to be digitally skilled. As Castañeda and Selwyn (2018) argue, digital technology shapes the needs and emotions of staff and students.

Furthermore, the TEs express the feeling of solitude in this process of learning, which clearly relates to the isolation in this profession, identified in previous research of the TE's scheduled life of planning and carrying out lessons on their own that limits possibilities to collaborate and conduct collegial interchange (Hadar \& Brody, 2010). The isolation can be connected to the TE's feeling of being solely responsible for gaining new knowledge and the inner demand of being in constant learning mode. Snow-Gerono (2005) concludes that the perceived isolation has been viewed as having restrictive and protective sides, visible also in the empirical material of this study. The restrictive side is the TEs expressing the feeling that digitalization and the use of digital technology is a trend and questioning the added value, and hence there appears to be some hesitation and a more selective approach. The protective side concerns the autonomy of TEs and their identity as a teacher. The isolation or solitude of the TE enables autonomy, in this case the possibility of choosing how to implement and use digital technology in instruction and teaching, and a possible way of hindering the individual's professional development.

In the data, there is an expressed desire for becoming familiar with the technology and to learn together with colleagues collectively, indicating the ambition to become part of a learning community. The TEs believe they are part of a semi-digital culture, a culture whose character traits include having 
substantial professional autonomy, an obligation to be both a teacher and a researcher and having a variety of approaches towards digitalization. Becoming a member of such a professional community would mean an opportunity for collaborative learning and exploring (Hadar \& Brody, 2010) and a professional opportunity for exploring attitudes towards the digital trend and adopting more of a pedagogical approach that is student-oriented (Drent \& Meelissen, 2008). Discussing together in a learning community what digitalization is and how digitalization should be used can be a way forward in developing a collective, strategic voice (Wenger \& Wenger Trayner, 2015), shared repertoire of resources, and a working consensus. A working consensus for teaching situations, courses or even educational programs, would reduce the sense of isolation for the TEs.

The second tension the study demonstrates concerns a lack of sufficient professional support for the TEs to make the jump from being in practice to acting in practice. Research shows that there should be both a bottom-up and a top-down perspective to create a long-lasting development and supportive conditions that stimulate a reflective behaviour and possibilities to experiment and explore (Drent \& Meelissen, 2008). Thus, the study reveals a top-down perspective on digitalization in teacher education, implementing digital tools and organizing courses and workshops mainly for administrative and informative purposes. Opportunities for the employed TEs to reflect and experiment, to create spaces for professional development, are lacking. As Berry (2009) asserts, the TE as a representative of a learning profession needs to develop professionally but professional development support is rarely provided. The findings thus verify the Avidov-Ungar and Forkosh-Baruch (2018) conclusion that functioning as a TE in the digital era requires support to strengthen the professional identity and to facilitate activities for professional development. In this perceived lack of professional support and development there is an underlying belief that higher education and the teacher education curriculum is adapting to digital trends without reflecting upon its affordances and challenges. The TEs in this study clearly call for collegial critical reflection on the added or the subtracted value of digitalization, its place in teacher education, and what digital competencies and digital approaches the TE and the pre-service teacher need to develop.

The third identified tension concerns the TE's views on digitalization and impact on education represented on several and varied levels in the empirical material: from digital tools improving their teaching, to transforming processes and practices, to being part of a technology-initiated revolution of education and society (Selwyn, 2017). The TEs who view digitalization of education in terms of the digital tools that improve their teaching also have ideas and a shorter path to use digital technology in their teaching. TEs who view digitalization on a more abstract level, as practices and processes, or even as a transformation of society, 
seem to have a longer path to working with it in practice. Their utterances show more overwhelming views regarding the digitalization of everyday life and the speed of change, and they become vague and unsure about what to do and how to carry out their work as TEs. They seek more of a discussion and more reflection upon whether and how digitalization improves teaching and learning for the preservice student, as Castañeda and Selwyn (2018) consider necessary. They have more of a focus on values and ethical issues and how these can be processed in the teaching.

\section{Conclusion}

In conclusion, this study offers insights into TEs' perceptions of their profession in relation to the digitalization of society and the perceived needs and consequences for the TE. It addresses the research gap in studies on TEs' work and what role the digitalization of society plays in the duties of a lecturer in higher education who is preparing future teachers for their profession, rather than being a study in how to use and implement digital technology in higher education. The study demonstrates the complex challenge of the TE, to teach and learn simultaneously in a profession of autonomy and responsibility, to move from being to acting in practice.

This in-depth analysis clearly shows that the TEs' perceived requirements and demands give rise to needs and consequences for the TE located in the intersection between a desire to learn in order to meet the demands of current developments in society and being professionally autonomous in a higher education institution that lacks targeted policy, strategy, and support to provide the necessary conditions. The study identifies in the TEs' statements a discrepancy between directives about their work and the actual professional practice. The study implies that breaking the TEs' perceived isolation is crucial for the TEs to develop professionally and move forward from merely being in practice to acting in practice. It is essential to find support in the policies and strategies of their organizations as well as among their colleagues, for each TE to find an approach to the digitalization of teacher education. Further research needs not only to address the conditions of TEs in relation to the students and teaching as Castañeda and Selwyn (2018) points out, but also, as this study implies, from the perspective of working conditions of university lecturers. 
Journal of Praxis in Higher Education, Vol. 1 No. 1 (2019) 


\section{Author biographies}

Anna Roumbanis Viberg is a $\mathrm{PhD}$ student in Education with a specialization in work-integrated learning at University West, Sweden. Her research interest includes how digitalization of society affects the teacher educator's professional development, agency, and identity.

Karin Forslund Frykedal, $\mathrm{PhD}$, is Professor of Education at University West, Sweden. Her scientific activity lies within both the educational and the social psychological research field with a strong focus on group research mainly connected to groups, group processes, learning, and education.

Sylvana Sofkova Hashemi has a $\mathrm{PhD}$ in computational linguistics and is Associate Professor in educational science at the University of Gothenburg, Sweden. Her research concerns both cognitive and socio-cultural perspectives on literacy and text competencies in today's media landscape. She has extensive experience of practiceclose research with teachers dealing with technology mediated teaching and learning, pupils' communicative strategies, and teachers' professional development. 


\section{References}

Avidov-Ungar, O., \& Forkosh-Baruch, A. (2018). Professional identity of teacher educators in the digital era in light of demands of pedagogical innovation. Teaching and Teacher Education, 73, 183-191. doi:10.1016/j.tate.2018.03.017

Bartolomé, A., Castañeda, L., \& Adell, J. (2018). Personalisation in educational technology: the absence of underlying pedagogies. International Journal of Educational Technology in Higher Education, 15(1), 14.

Berry, A. (2009). Professional self-understanding as expertise in teaching about teaching. Teachers and Teaching, 15(2), 305-318. doi:10.1080/13540600902875365

Braun, V., \& Clarke, V. (2006). Using thematic analysis in psychology. Qualitative Research in Psychology, 3(2), 77-101. doi:10.1191/1478088706qp063oa

Brennen, J. S., \& Kreiss, D. (2016). Digitalization. In K. B. Jensen, E. W. Rothenbuhler, J. D. Pooley, \& R. T. Craig (Eds.), The International Encyclopedia of Communication Theory and Philosophy, Chichester: Wiley-Blackwell. https://doi.org/10.1002/9781118766804.wbiect111

Castañeda, L., \& Selwyn, N. (2018). More than tools? Making sense of the ongoing digitizations of higher education. International Journal of Educational Technology in Higher Education 15[22]. https://doi.org/10.1186/s41239-018-0109-y

Decuypere, M., \& Simons, M. (2016). Relational thinking in education: Topology, sociomaterial studies, and figures. Pedagogy, Culture \& Society, 24(3), 371-386.

Drent, M., \& Meelissen, M. (2008). Which factors obstruct or stimulate teacher educators to use ICT innovatively? Computers \& Education, 51(1), 187199. doi:10.1016/j.compedu.2007.05.001

Farjon, D., Smits, A., \& Voogt, J. (2019). Technology integration of pre-service teachers explained by attitudes and beliefs, competency, access, and experience. Computers \& Education, 130, 81-93. doi:10.1016/j.compedu.2018.11.010

Fors, A. C. (2010). The beauty of the beast: The matter of meaning in digitalization. AI \& Society, 25(1), 27-33. doi:10.1007/s00146-009-0236-z

Gerbic, P. (2011). Teaching using a blended approach - What does the literature tell us? Educational Media International, 48(3), 221-234. doi:10.1080/09523987.2011.615159

Gudmundsdottir, G. B., \& Hatlevik, O. E. (2017). Newly qualified teachers' professional digital competence: Implications for teacher education. 
European Journal of Teacher Education, 41(2), 214-231. doi:10.1080/02619768.2017.1416085

Hadar, L., \& Brody, D. (2010). From isolation to symphonic harmony: Building a professional development community among teacher educators. Teaching and Teacher Education, 26(8), 1641-1651. doi:10.1016/j.tate.2010.06.015

Harvey, D. M., \& Caro, R. (2017). Building TPACK in preservice teachers through explicit course design. TechTrends, 61(2), 106-114. doi:10.1007/s11528-016-0120-x

Instefjord, E., \& Munthe, E. (2016). Preparing pre-service teachers to integrate technology: An analysis of the emphasis on digital competence in teacher education curricula. European Journal of Teacher Education, 39(1), 7793. doi:10.1080/02619768.2015.1100602

Istenic Starčič, A., Cotic, M., Solomonides, I., \& Volk, M. (2016). Engaging preservice primary and preprimary school teachers in digital storytelling for the teaching and learning of mathematics. British Journal of Educational Technology, 47(1), 29-50. doi:10.1111/bjet.12253

Jenkins, N., Bloor, M., Fischer, J., Berney, L., \& Neale, J. (2010). Putting it in context: The use of vignettes in qualitative interviewing. Qualitative Research, 10(2), 175-198. doi:10.1177/1468794109356737

Jonker, H., März, V., \& Voogt, J. (2018). Teacher educators' professional identity under construction: The transition from teaching face-to-face to a blended curriculum. Teaching and Teacher Education, 71, 120-133. doi:10.1016/j.tate.2017.12.016

Kim, C., Kim, M. K., Lee, C., Spector, J. M., \& DeMeester, K. (2013). Teacher beliefs and technology integration. Teaching and Teacher Education, 29, 76-85. doi:10.1016/j.tate.2012.08.005

Knight, S. L., Lloyd, G. M., Arbaugh, F., Gamson, D., McDonald, S. P., \& Nolan Jr, J. (2014). Professional development and practices. Journal of Teacher Education, 65(4), 268-270. doi:10.1177/0022487114542220

Kolb, D. A. (2014). Experiential learning: Experience as the source of learning and development. New Jersey: FT press.

Korthagen, F., Loughran, J., \& Lunenberg, M. (2005). Teaching teachers Studies into expertise of teacher educators: An introduction to this theme issue. Teaching and Teacher Education, 21(2), 107-115. doi:10.1016/j.tate.2004.12.007

Koster, B., Dengerink, J., Korthagen, F., \& Lunenberg, M. (2008). Teacher educators working on their own professional development: Goals, activities and outcomes of a project for the professional development of teacher educators. Teachers and Teaching, 14(5-6), 567-587. doi:10.1080/13540600802571411 
Lunenberg, M. (2010). Characteristics, scholarship and research of teacher educators. In P. Peterson, E. Baker, B. McGaw (Eds.), International encyclopedia of education, $3^{\text {rd }}$ ed. (pp. 676-680). Oxford: Elsevier Ltd.

Lunenberg, M., Dengerink, J., \& Korthagen, F. (2014). The professional teacher educator: Roles, behaviour, and professional development of teacher educators. Rotterdam: Springer Science \& Business Media.

McGee, A., \& Lawrence, A. (2009). Teacher educators inquiring into their own practice. Professional Development in Education, 35(1), 139-157. doi:10.1080/13674580802268994

Mouza, C., Karchmer-Klein, R., Nandakumar, R., Ozden, S. Y., \& Hu, L. (2014). Investigating the impact of an integrated approach to the development of preservice teachers' technological pedagogical content knowledge (TPACK). Computers \& Education, 71, 206-221. doi:10.1016/j.compedu.2013.09.020

OECD. (2017). Education at a glance. Retrieved 2019-10-31 from: http://www.oecd.org/education/education-at-a-glance/

Patton, K., \& Parker, M. (2017). Teacher education communities of practice: More than a culture of collaboration. Teaching and Teacher Education, 67, 351-360. doi:10.1016/j.tate.2017.06.013

Quinn-Patton, M. (2002). Qualitative research and evaluation methods. London: Sage Publications.

Reich, A., \& Hager, P. (2014). Problematising practice, learning and change: Practice-theory perspectives on professional learning. Journal of Workplace Learning, 26(6/7), 418-431. doi:10.1108/jwl-02-2014-0016

Selwyn, N. (2017). Skolan och digitaliseringen: blir utbildningen bättre med digital teknik. [Is technology good for education?]. Göteborg: Daidalos.

SFS (1993:100). Higher education ordinance. Stockholm: Utbildningsdepartementet.

Snow-Gerono, J. L. (2005). Professional development in a culture of inquiry: PDS teachers identify the benefits of professional learning communities. Teaching and Teacher Education, 21(3), 241-256. doi:10.1016/j.tate.2004.06.008

Swedish Ministry of Education. (2017). Nationell digitaliserings strategi för skolväsendet. U2017/04119/S.

Swedish Research Council. (2019). Forskningsetiska principer inom humanistisksamhällsvetenskaplig forskning. Retrieved 2019-10-31 from: http://www.codex.vr.se/texts/HSFR.pdf

Trent, J. (2013). Becoming a teacher educator: The multiple boundary-crossing experiences of beginning teacher educators. Journal of Teacher Education, 64(3), 262-275. doi:10.1177/0022487112471998 
Uerz, D., Volman, M., \& Kral, M. (2018). Teacher educators' competences in fostering student teachers' proficiency in teaching and learning with technology: An overview of relevant research literature. Teaching and Teacher Education, 70, 12-23. doi:10.1016/j.tate.2017.11.005

Wenger, E., \& Wenger Trayner, B. (2015). Introduction to communities of practice. A brief overview of its concepts and its uses. Retrieved 2019-1031 from: https://wenger-trayner.com/introduction-to-communities-ofpractice/ 